\title{
Synergies between energy efficiency measures and air pollution in Italy
}

\author{
T. Pignatelli ${ }^{1}$, M. Bencardino ${ }^{1}$, M. Contaldi $^{2}$, F. Gracceva $^{1}$ \\ \& G. Vialetto ${ }^{1}$ \\ ${ }^{1}$ ENEA, National Agency for New Technology, \\ Energy and the Environment, Rome, Italy \\ ${ }^{2} A P A T$, Environment Protection and Technical Services Agency, Rome, \\ Italy
}

\begin{abstract}
Greenhouse gases, such as carbon dioxide, and atmospheric pollutants, such as sulphur, nitrogen oxides and particulate matter, are mainly generated from energy production and consumption. For several years the European Commission has given great importance to the control of atmospheric pollutants, establishing emission limits for LCPs (Large Combustion Plants), as well as national emission ceilings, at Member State level. The development of energy scenarios is the most crucial step in creating emission projections of air pollutants and greenhouse gases from energy sources, and "business as usual" (b.a.u.) energy scenarios are normally considered to elaborate upon reference emission scenarios, on the basis of the abatement measures ruled in the current legislation. However, the b.a.u. energy scenarios could be deeply modified by the implementation of policies and measures aimed at energy saving, so emphasising the synergies existing between Air Quality and Climate Change, and at the same time reducing the abatement costs to ultimately protect human health and the environment. From this point of view, energy efficiency and renewable sources comprise two essential policy instruments to achieve the final objective. In this paper, an alternative energy scenario, taking into account a set of policies for increasing the energy efficiency and the share of renewable sources, is analysed and assessed in terms of decreased air pollutants and carbon dioxide emissions. Synergies and trade offs in air pollution are also analysed through a comparative and quantitative analysis of the reference and alternative scenarios, under the commitment to achieve the reduction objectives. The study has been carried out by the GAINS-Italy model, a national integrated assessment model developed by ENEA in collaboration with the International Institute for Applied Systems Analysis (IIASA) in Laxenburg. The modelling activity is ongoing under the sponsorship of the Italian Ministry for the Environment, the Land and the Sea.
\end{abstract}

Keywords: air pollution, climate change, integrated assessment modelling, emission scenarios, cost curves, GAINS, GHGs. 


\section{Introduction}

In recent years, in the framework of the European Union as well as in the larger context of the UN-ECE Convention on Long Range Transboundary Air Pollution (CLRTAP), the links between Climate Change and Air Pollution have become more and more evident. Greenhouse Gases (GHGs), such as CO2, and air pollutants, such as Sulphur Oxides (SO2), Nitrogen Oxides (NO2) and Particulate Matter (PM) are essentially generated by the combustion process of fossil fuels. International agreements, such as the Kyoto Protocol and the Gothenburg Protocol, call for a substantive reduction in the emissions of those pollutants in the coming decades in order to meet environmental and human health preservation objectives. As a consequence, the national experts, while developing energy scenarios, have placed increasing attention on including measures suitable to simultaneously address the envisaged reductions both in GHGs and Air Pollutant emissions. For these reasons, the Italian Ministry for the Environment and the Protection of the Land and the Sea has mandated ENEA to explore the potential in emission reduction associated with a number of structural and technical measures that have already been planned to be implemented in coming years. In this analysis, such a potential is then quantified by the comparison with the estimated emissions from a reference scenario, which do not include the measures under assessment. The comparative analysis of this study also allows one to highlight the advantages and disadvantages of the selected measures, with the ultimate objective of providing the policy makers with sufficient elements to define cost-effective policies to combat both Climate Change and Air Pollution.

\section{Description of the analysis tool}

The analyses reported in this study have been developed by the Integrated Assessment Model GAINS-Italy, the result of a research project jointly carried out by ENEA and IIASA (International Institute for Applied Systems Analysis, Laxenburg, Austria). GAINS-Italy derives directly from the analogous continental model GAINS-Europe (Klassen [1]), which in turn is an extension to the GHGs of the RAINS-Europe model (Amann et al. [2]). GAINS-Italy, similarly to its precursor version RAINS-Italy (Vialetto et al. [6]), computes emissions scenarios, at 5 year intervals, for $\mathrm{SO}_{2}, \mathrm{NOx}, \mathrm{NH}_{3}, \mathrm{VOCs}, \mathrm{PM}$, Ozone and GHGs, on the basis of data concerning the anthropogenic activities (energy consumptions, industrial production, livestock, agriculture etc.) and a long list of applicable abatement technologies, which the user selects in the so called Control Strategy, according to the implementation of measures due to the Current Legislation (CLE Strategy) or alternative Reduction Strategies. Once emissions are calculated through the use of Atmospheric Transfer Matrices, elaborated by the Eulerian Model AMS (Atmospheric Modelling System, Zanini et al. [3]), representing, in the form of exchange coefficients, the source-receptor relationship between emission sources and the single cell, $20 \mathrm{~km} \times 20 \mathrm{~km}$, in the calculus domain, the dispersion of the emissions over the territory is calculated 
and mapped. Then the estimated emission depositions and concentrations are compared with "critical loads" and "critical levels", cell by cell, to have an assessment of the environmental impact in terms of acidification and eutrophication and ground level ozone (EMEP [4]). Moreover, the impact of PM2,5 and Ozone on human health can be also estimated, in terms of "Life Expectancy Reduction" for PM2,5 (Mechler et al. [5]) and "Premature Deaths" for Ozone, on the basis of epidemiological studies and statistical analysis (Amann et al. [2]). Abatement costs can also be evaluated, including investment and operative costs, to compare alternative control strategies and ultimately identifying the most cost-effective solution. The analysis process described is summarized in the flow diagram in Fig. 1. In this study, the analysis is limited to the emission analysis only.
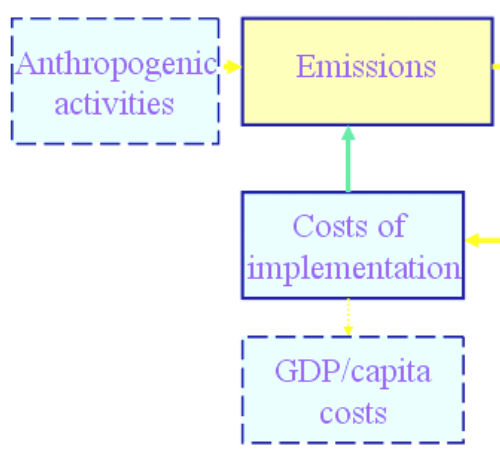
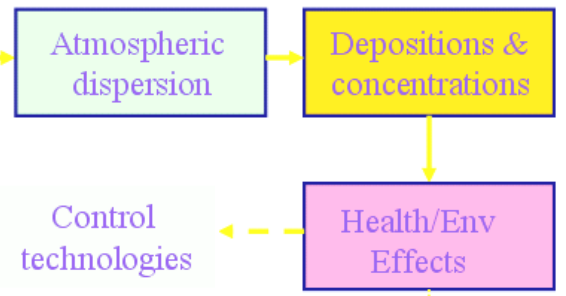

Depositions \& concentrations

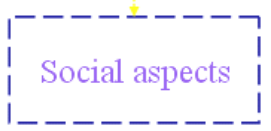

Figure 1: $\quad$ Flow diagram of the Integrated Assessment Approach in GAINS.

In order to better understand the relationship between the input and the output in the GAINS-Italy Model, a simplified schema is reported in Fig. 2

The left and bottom boxes are input data selected by the user. In particular, the energy scenarios are developed exogenously by a suitable energy model called Markal-Italy, and then imported as input in GAINS-Italy, once properly re-formatted and re-aggregated for GAINS. The Control Strategy is the penetration of the abatement technologies, along time, in terms of the percentage of "covered" input data (usually called activity level), for any combination of all the sector, sub-sector, fuel or technology considered in the GAINS-Model, at any year under analysis, e.g. the percentage of input coal, in Power Pants, where Electro-Static Precipitator (ESP) is applied, at years 2000, 2005, 2010 etc.

\section{Assumption of the analysis}

As mentioned above, the main objective of this study is the estimation of the potential emission reductions associated with the introduction of a series of measures into an alternative energy scenario (here called "ALT"), in comparison 


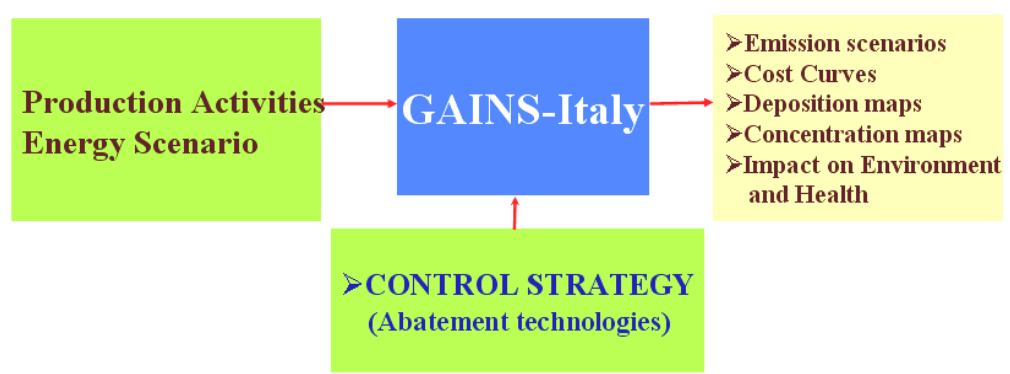

Figure 2: $\quad$ Simplified schema input/output in GAINS-Italy.

Table 1: Additional measures characterizing the ALT scenario with respect the TEND scenario.

\begin{tabular}{||l||}
\hline INCREASED ELECTRIC GENERATION FROM RENEWABLE \\
ENERGIES (REN) \\
\hline $\begin{array}{l}\text { Increased production of fuel from municipal wastes, up to } 1 / 3 \text { of the total } \\
\text { annual production of wastes }\end{array}$ \\
\hline $1000 \mathrm{Mw}$ installed power at 2015, from photo-voltaic plants \\
\hline $15 \%$ of energy demand for heating supplied by remote centralized plants \\
\hline Increased share of coal (CCS included) in electricity production from 2020 \\
\hline Increased use of low consumption bulbs up to triple of current trend \\
\hline $\begin{array}{l}\text { Electric power: increased share of high energy efficiency engines over } 50 \% \text { of } \\
\text { the market, at } 2015\end{array}$ \\
\hline $\begin{array}{l}\text { House appliances: high efficiency energy appliances doubled with respect the } \\
\text { current trend }\end{array}$ \\
\hline Thermal solar power: $30 \%$ of demand at 2020 \\
\hline Thermal insulation: increased efficiency up to $10 \%$ consumption saving \\
\hline Transport Sector: bio-fuel share increased up to $7,5 \%$ at 2020 \\
\hline $\begin{array}{l}\text { Transport Sector: Low consumption vehicles share increased up to } 80 \% \text { of the } \\
\text { total new vehicles, at } 2020\end{array}$ \\
\hline Transport Sector: increased share of gas buses in public transport \\
\hline Freight Transport: Doubled share with respect the current value \\
\hline \hline
\end{tabular}

with a reference energy scenario (here called "TEND"). The TEND scenario is considered to be a business as usual (b.a.u.) scenario, where from the point of view of the emission controls implemented, the abatement measures included are those foreseen in the Current Legislation only (therefore the whole emission scenario is referred as CLE). The ALT scenario, instead, includes additional measures with respect to the reference scenario, concerning energy saving, higher energy efficiency and a higher share of renewable energy, which are summarized in Table 1. The emission controls associated with the ALT scenario are the same as in the TEND scenario, so that any difference in emissions is 
related to structural changes in the energy scenarios only. The measures listed in Table 1 have already been included in the national energy plan and formally adopted, at national level, from the Italian Ministry for Economic Development.

\section{Characterization of the scenarios from an energy perspective}

In order to better understand the results of this study as differences of the two scenarios analyzed, in terms of emission reduction achievable, it is useful to have a characterization of the two energy scenarios from the perspective of the input to the GAINS-Italy Model. Keeping in mind Fig. 2 and remembering that in this study only the energy content is different, comparing the TEND and the ALT scenarios, it becomes clear that any single change in the energy input is reflected in output, as a change in emissions. In Fig. 3 the two scenarios are compared in terms of global energy consumption. The ALT scenario is characterized by lower global energy consumption, starting from 2010 and further increasing until 2030. The global energy content is also reported in Table 2 in absolute values (PJoule). In Fig. 4, the comparison between the TEND and the ALT scenarios are reported in terms of energy consumption per sector at 2020. The additional measures included in the ALT scenario have effect mainly in the Industry, Residential and Transport sectors as well as in the Power Plant sector, generally reducing energy consumptions in the ALT scenario.

\section{Results and discussion}

In Figs. 5-8 the results of the comparative analysis are reported. The red line is the emission ceiling, at 2010, established by the EU Directive 2001/81/CE. For SOx and NOx there is no significant difference in terms of emission reductions

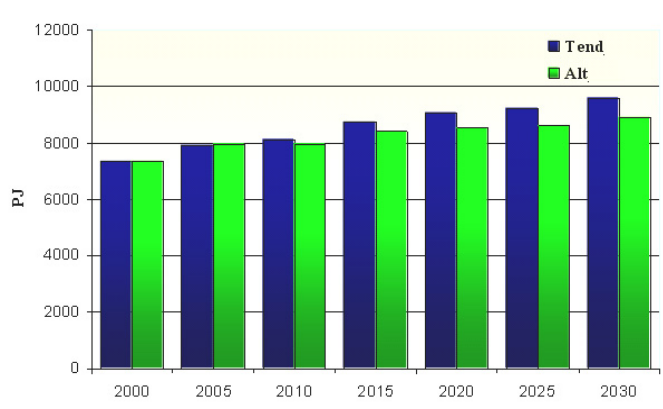

Figure 3: Comparison between the TEND and the ATL scenarios, as global energy content (PJoule). 


\begin{tabular}{|c|c|c|}
\hline \multicolumn{3}{|c|}{ Total Energy Content } \\
\hline Tend & Alt & Year \\
\hline 7311 & 7332 & 2000 \\
\hline 7919 & 7936 & 2005 \\
\hline 8121 & 7965 & 2010 \\
\hline 8743 & 8386 & 2015 \\
\hline 9057 & 8502 & 2020 \\
\hline 9219 & 8593 & 2025 \\
\hline 9600 & 8905 & 2030 \\
\hline
\end{tabular}

Table 2: Comparison between the TEND and the ATL scenarios (absolute values Joule).

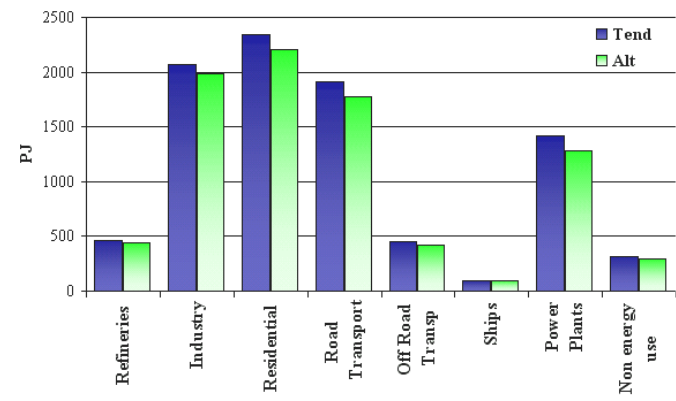

Figure 4: Energy content per sector in the TEND and the ALT scenarios.
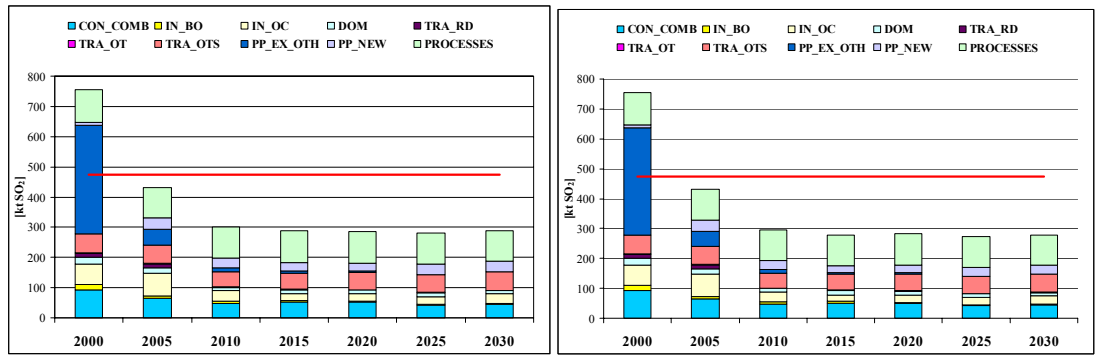

Figure 5: SOx emissions in the TEND (right) and the ALT (left) scenarios, at 2010 , by sector, in $\mathrm{kt}$. 

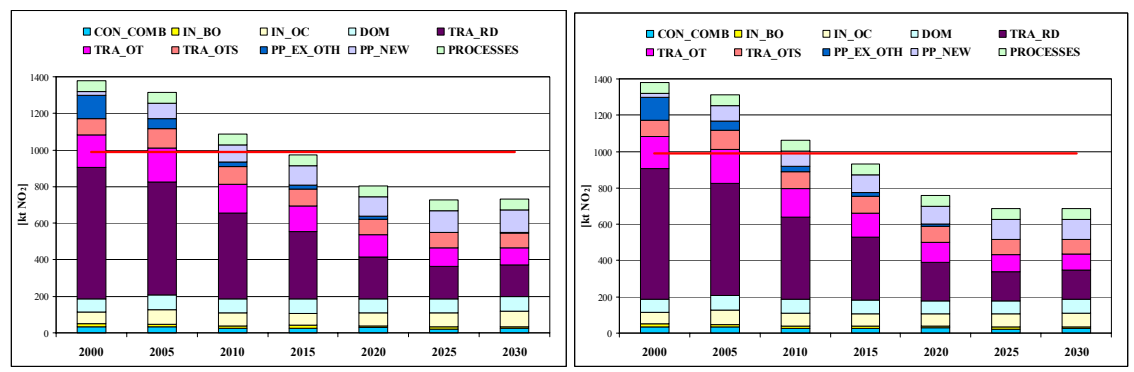

Figure 6: NOx emissions in the TEND (right) and the ALT (left) scenarios, at 2010 , by sector, in kt.

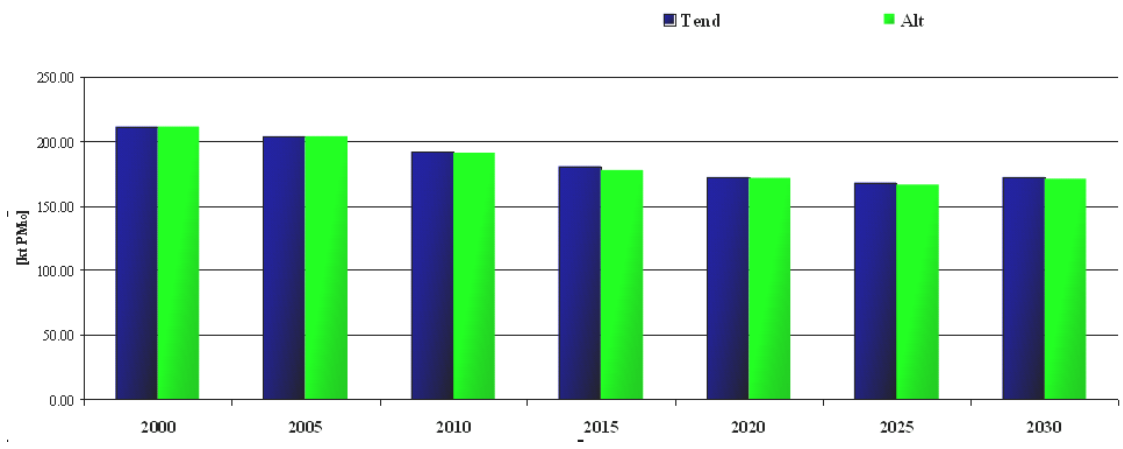

Figure 7: Total PM emissions in the TEND and the ALT scenarios, in kt.

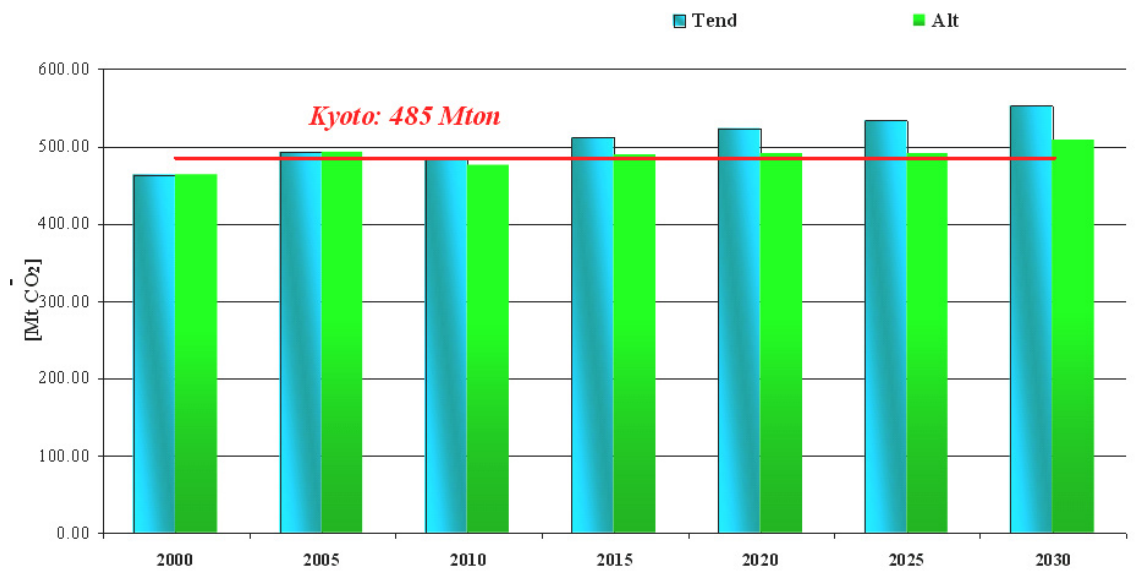

Figure 8: $\mathrm{CO} 2$ emission in the TEND and the ALT scenarios, absolute values, in Mt. 
and compliance with the Directive, for NOx the ceiling is exceeded and for PM no ceiling is yet established, although the emissions are quite similar in both scenarios. For CO2 emissions a significant reduction is noted after 2015, although at 2010 the achievement of the Kyoto target is quite uncertain, as even in the ALT scenario after 2015 the target is constantly exceeded. Moreover, the Transport sector is identified as the most critical. Therefore, it can be concluded that the measures listed in Table 1, although introducing some benefits in terms of emission reductions, mainly concerning $\mathrm{CO}_{2}$, do not allow one to achieve compliance with the EU regulation (NOx ceiling) and do not ensure successful fulfilment of the Kyoto target after 2010.

Being as the ultimate perspective of Integrated Assessment Modelling is to provide the policy makers with elements for defining cost-effective policies, the suggestion coming from this study is to further increase efforts in the direction of the already planned measures, especially in the use of renewable energies and improving energy efficiency, so that investment costs in the implementation of the measures are do not vanish by missing environmental and human health protection objectives. It should also be considered that additional costs are associated with incompliance with the EU Directives due to penalties.

\section{References}

[1] Klassen G., "The Extension of the RAINS Model to Greenhouse Gases"

[2] Amann M., Cofala J., Heyes C., Klimont Z., Mechler R., Posch M., Schöpp W., "The RAINS model. Documentation of the model approach prepared for the RAINS peer review 2004", February 2004.

[3] Zanini G., Pignatelli T., Monforti F., Vialetto G., Vitali L., Brusasca G., Calori G., Finardi S., Radice P., Silibello C.; The MINNI Project: An Integrated Assessment Modelling System for policy making. In Zerger, A. and Argent, R.M. (eds) MODSIM 2005 International Congress on Modelling and Simulation. Modelling and Simulation Society of Australia and New Zealand, December 2005, pp. 2005-2011. ISBN: 0-9758400-2-9. http://www.mssanz.org.au/modsim05/papers/zanini.pdf

[4] EMEP, 2003. Transboundary acidification, eutrophication and ground level ozone in Europe. Part I: Unified EMEP model description, EMEP status Report 1/2003.

[5] Mechler R., Amann M., Shoepp W., "A methodology to estimate changes in statistical life expectancy due to the control of particulate matter air pollution", 2002.

[6] Vialetto, G., Contaldi, M., De Lauretis, R., Lelli, M., Mazzotta, V., Pignatelli, T., 2005. Emission Scenarios of Air Pollutants in Italy using Integrated Assessment Models. Pollution Atmosphérique 185, 71. 